\title{
Quality of Water the Slum Dwellers Use: The Case of a Kenyan Slum
}

\author{
Elizabeth Wambui Kimani-Murage and Augustine M. Ngindu
}

\begin{abstract}
As a result of rapid urbanization in a context of economic constraints, the majority of urban residents in sub-Saharan Africa live in slums often characterized by a lack of basic services such as water and sewerage. Consequently, the urban poor often use inexpensive pit latrines and at the same time may draw domestic water from nearby wells. Overcrowding in slums limits the adequate distance between wells and pit latrines so that micro-organisms migrate from latrines to water sources. Sanitary practices in these overcrowded slums are also poor, leading to contamination of these wells. This study sought to assess sanitary practices of residents of a Kenyan urban slum and fecal contamination of their domestic water sources. This cross-sectional study involved 192 respondents from Langas slum, Kenya. Forty water samples were collected from the water sources used by the respondents for laboratory analysis of coliforms. Of these 40 samples, 31 were from shallow wells, four from deep wells, and five from taps. Multiple-tube fermentation technique was used to enumerate coliform bacteria in water. The study found that most people (91\%) in the Langas slum used wells as the main source of domestic water, whereas the rest used tap water. Whereas most people used pit latrines for excreta disposal, a substantial percentage (30\%) of children excreted in the open field. The estimated distance between the pit latrines and the wells was generally short with about $40 \%$ of the pit latrines being less than $15 \mathrm{~m}$ from the wells. The main domestic water sources were found to be highly contaminated with fecal matter. Total coliforms were found in $100 \%$ of water samples from shallow wells, while $97 \%$ of these samples from shallow wells were positive for thermotolerant coliforms. Three out of the four samples from deep wells were positive for total coliforms, while two of the four samples were positive for thermotolerant coliforms. None of the samples from taps were positive for either total or thermotolerant coliforms. Because the presence of thermotolerant coliforms in water indicates fecal contamination, facilitated by the proximity between the wells and pit latrines, the study suggests that the pit latrines were a major source of contamination of the wells with fecal matter. However, contamination through surface runoff during rains is also plausible as indiscriminate excreta disposal particularly by children was also common. Owing to the fecal contamination, there is a high possibility of the presence of disease pathogens in the water; thus, the water from the wells in Langas may not be suitable for human consumption. To address this problem, treatment of the water at community or household level and intensive behavioral change in sanitary practices are recommended. Efforts should be made to provide regulated tap water to this community and to other slums in sub-Saharan Africa where tap water is not accessible. However, more sampling of different water sources is recommended.
\end{abstract}

KEYWORDS Water, Water quality, Sanitation, Sanitary practices, Coliforms, Contamination, Slums, Urban poor, Poverty, Urbanization, Africa, Kenya

Kimani-Murage is with the African Population and Health Research Center, Nairobi, Kenya; Ngindu is with the Moi University, Eldoret, Kenya.

Correspondence: Elizabeth Wambui Kimani-Murage, MPH, BSc, African Population and Health Research Center, P.O. Box 10787, 00100-GPO, Nairobi, Kenya. (E-mail: lizmurage_2003@yahoo.com) 


\section{INTRODUCTION}

Rapid urban growth in a climate of economic constraints has resulted in the majority of residents in Africa's large cities, and an increasing proportion of Africans overall, living in overcrowded slums and shantytowns. In these slums and shantytowns, health conditions and livelihood opportunities are poor. ${ }^{1-3}$ Available evidence indicates that the poor urban residents of Africa exhibit higher morbidity, have poor access to health services, and consequently exhibit higher mortality rates than residents of other areas including rural residents. ${ }^{4-8}$

The situation in Kenya is similar to other situations in Africa. The proportion of urban population in Kenya nearly doubled between 1980 and 1998, increasing from 16 to $31 \%$. ${ }^{9}$ Rapid urbanization amid economic degradation in Kenya has resulted in an increased proportion of people living in absolute poverty in the urban areas. ${ }^{10}$ Therefore, poverty has increasingly become a crucial urban problem in Kenya leading to mushrooming of informal settlements in the urban parts of Kenya where the urban poor find shelter. This has overwhelmed the environmental health resources in urban areas. Because of their illegal status, residents of informal settlements in Kenya do not receive government services such as water, drainage, sewerage, and rubbish collection. Consequently, informal settlements are characterized by poor environmental conditions that predispose their inhabitants to poor health outcomes. ${ }^{4}$ Evidence shows that children of poor families in urban areas of Kenya exhibit poorer health conditions than their rural counterparts. According to a report by African Population and Health Research Center (APHRC) in 2002, ${ }^{4}$ infant and child mortality risks are particularly higher in the slums of Nairobi than those observed in other urban areas and in rural Kenya. For instance, the under five mortality was $35 \%$ higher among slum residents in Nairobi than among the rural population in Kenya. The report attributes these patterns to poor water and sanitation in these slum settlements. $^{4}$

An adequate supply of safe drinking water is universally recognized as a basic human need. Yet millions of people in the developing world do not have ready access to an adequate and safe water supply. By 1996, the number of people without access to safe water in urban areas was rising sharply in developing countries as a result of rapid urbanization, much of which was occurring in periurban and slum areas. ${ }^{11}$ Because the United Nations projects a rapid population growth in urban areas between 2000 and 2030, ${ }^{12}$ access to safe drinking water and adequate sanitation in urban areas is likely to worsen unless there is a drastic policy change to cater to the needs of the urban poor.

Human excreta and the lack of adequate personal and domestic hygiene have been implicated in the spread of many infectious diseases including cholera, typhoid, hepatitis, polio, cryptosporidiosis, ascariasis, and schistosomiasis. It is estimated that one-third of deaths in developing countries are caused by the consumption of contaminated water and on average as much as one-tenth of each person's productive time is sacrificed to water-related diseases. ${ }^{13}$ The World Health Organization estimates that 2.2 million people die annually from diarrhea diseases and that $10 \%$ of the population of the developing world are severely infected with intestinal worms related to improper waste and excreta management. ${ }^{14,15}$ In Kenya, diarrheal diseases are among the major illnesses affecting children of the slum residents. According to the report by APHRC in 2002, prevalence of diarrhea was $32 \%$ among children below 5 years of age in the slums, which is double the rate for Nairobi and the national average. ${ }^{4}$ 
Where ground water is used as a source of domestic water, use of pit latrines is not recommended because the two are incompatible unless the water table is extremely low and soil characteristics are not likely to contribute to contamination of ground water. Where they coexist, although it is difficult to give a general rule for all soil conditions, the commonly used guideline is that the well should be located in an area higher than and at least $15 \mathrm{~m}$ from the pit latrines and should be at least 2 $\mathrm{m}$ above the water table. Available evidence shows that increased lateral separation between the source of pollution and groundwater supply reduces the risk of fecal pollution. ${ }^{16}$ Coexistence of on-site sanitation and use of underground water has in the past been mainly confined to the rural areas where there is adequate land to allow for adequate distance between pit latrines and shallow wells. With the rapid urbanization and rapid expansion of slum settlements in sub-Saharan Africa, onsite sanitation and underground water are used in some urban areas because they are affordable options in the absence of government-supplied services. However, the congestion in the urban slums does not allow for adequate distance between the wells and the pit latrines, which allows micro-organisms to migrate from fecal contents into the underground water sources. Furthermore, poor sanitary practices (for example, disposal of human excreta) in these slum areas lead to contamination of water and consequently water-borne diseases. It is in this context and in the context of high levels of diarrheal diseases in the urban slums in Kenya that this study sought to assess the sanitary practices and the fecal contamination of domestic water sources in an urban slum in Eldoret, Kenya.

\section{STUDY CONTEXT}

The study was conducted between January and June 1999 in Langas, an urban slum in Eldoret municipality, Kenya, less than $10 \mathrm{~km}$ from Eldoret town. Eldoret town is located in the Rift Valley Province, about $330 \mathrm{~km}$ north west of Nairobi. Eldoret, the headquarter of Uasin Gishu District, is one of the fastest growing urban areas in Kenya. Langas falls under high density, low-income areas of the Eldoret municipality. It is divided into four administrative blocks that are further subdivided into about 2,500 plots. Each plot (1/8 of an acre) has between one and 30 households each with an average of six occupants. Settlement in Langas began in 1965 and at the time there were no basic services. Early settlers dug shallow wells for their water needs. ${ }^{17}$ The water table is high, and this raises the possibility of ground water contamination where on-site sanitation systems are in use.

\section{METHODOLOGY}

A cross-sectional study design was used and a sample of 192 households* was selected through multistage sampling technique as follows: two out of the four administrative blocks were randomly picked and from the two blocks, 192 plots were picked. From each of the selected plots, one household was selected to participate. The 192 households were selected as follows: starting from one corner of each of the blocks and walking across the two blocks in a more or less a diagonal

\footnotetext{
"Initially, the plan was to interview respondents from 384 households (calculated through a method for calculating a simple random sample). However, financial and logistic feasibility could not allow for the whole sample to be interviewed, and given the nature of the slum where many people shared one source of water and one toilet facility, the sample size of 192 (half of the sample initially calculated) was considered adequate.
} 
line, about every plot on the diagonal line was selected until the sample of 192 was reached. From each of these plots, one household was selected to represent the plot (this depended mainly on availability of respondents and their willingness to participate), and the first household to be contacted in a selected plot was considered for recruitment into the sample. From the household, a credible respondent was interviewed. A credible respondent was a resident of the selected household who was aged 18 years or above.

For water sampling, 20 samples were taken from water points in each of the two blocks to make a total of 40 samples. This number for water samples was determined by financial and logistical feasibility. In most circumstances, residents of a plot shared one water source and there was roughly one water point per plot. In a few cases, several plots shared a water point. To get the 40 samples, every fourth household" of the 192 households included in the interview sample was asked their source of water and a water sample was taken from this source so long as it had not already been taken. In the event that a previous fourth household shared the source with the current household, the source for the immediate next household in the study sample was considered. Of the 40 water samples, 31 were from shallow wells (defined as a hand-dug well), four from deep wells (defined as a drilled well) and five from taps (referring to tap water from the municipal council distribution system). Using the above described criteria, only one deep well was selected and purposive sampling was then used to get three other such wells, consequently including all the deep wells that were used by the study sample.

Questionnaires were administered to the 192 selected households to obtain information on the type of toilet facility used, major source of domestic water, method of human waste disposal, whether drinking water was boiled, and the perceptions of possible sources of water contamination in the area. For the method of excreta disposal and water source, the main method and source were considered in instances where there was more than one method or source, respectively. The distance between the pit latrines used by the 192 households and the wells (in cases where they used wells) was estimated. We also observed sanitation practices.

Water samples were collected aseptically with sterile sampling bottles. The samples were transported within 2 hours of collection in a cool box containing ice packs to the Faculty of Health Sciences, Moi University microbiology laboratory for analysis. Fecal contamination of the water was determined through isolation of indicator organisms, total coliforms, and then thermotolerant (fecal) coliforms, through multiple-tube fermentation (MTF) technique. Probability tables (McCrady tables) were used to determine the Most Probable Number (MPN) estimates of the coliform organisms per $100 \mathrm{ml}$ of water. Analysis of data was generally descriptive, involving determination of frequencies. Stata statistical package was used to analyze the data.

\section{RESULTS}

\section{Method of Excreta Disposal}

The majority of respondents $(98 \%)$ said that adults used pit latrines, whereas the rest said adults defecated indiscriminately. Similarly, a majority of respondents $(70 \%)$

\footnotetext{
"The fourth household from which to take a water sample was determined as the household for interviews were recruited.
} 
TABLE 1 Source of domestic water among 192 sampled households in Langas Slum, Kenya

\begin{tabular}{lcr}
\hline Source of domestic water & Number & Percent \\
\hline Tap & 17 & 8.9 \\
Shallow well & 171 & 89.1 \\
Deep well & 4 & 2.1 \\
Total & 192 & 100 \\
\hline
\end{tabular}

said that children used pit latrines, whereas $30 \%$ said children used open field/ defecated indiscriminately. Most of the pit latrines (95\%) in the community were traditional, whereas the rest were ventilated improved pit latrines (VIP latrines). A walk through the community confirmed the report that some people excreted indiscriminately as human excreta was observed strewn all over the compounds.

\section{Source of Domestic Water}

Most people $(89 \%)$ said they used shallow wells as the major source of domestic water, whereas $2 \%$ said they used water from deep wells and the rest said they used tap water from the municipal council (Table 1). The shallow wells often had no concrete slab and often the aperture was not covered at all or was poorly covered with a loose lid that was not lockable, whereas the deep wells had a piped system. Those who used deep wells were mainly the more affluent people in the community who often owned the plot in which the well was situated. Tap water was mainly from water kiosks where water was being sold to the slum residents. Respondents who did not use the tap water said that the water from water kiosks was expensive and unaffordable to be used for domestic purposes. " Problems of unreliability were mentioned as hindering use of tap water from the kiosks as some respondents said that sometimes the kiosk near their house could remain closed for a whole day or more. Some of the respondents reported that the nearest water kiosk was too far from their homes.

\section{Distance between Pit Latrine and Well}

The wells were very close to the pit latrines. In many circumstances (38\%), the distance between the wells and the pit latrines was estimated to be less than $15 \mathrm{~m}$ (the commonly used guideline is that the distance should be at least $15 \mathrm{~m}$ ). Most wells (about 59\%) were estimated to be at a distance between 15 and $30 \mathrm{~m}$ from the pit latrines (Table 2). The distance between pit latrines and wells for the wells from which water samples were taken was similar to that of other wells (Table 3 ).

\section{Boiling of Drinking Water}

Despite the short distance estimated between the pit latrines and the wells and the poor sanitary practices like indiscriminate excreta disposal, only $42 \%$ of those who reported using wells said they boiled their drinking water, when asked if they did.

\section{Residents' Perception of Contamination}

Respondents pointed out various possible sources of contamination of the water sources in the area. These included children dipping dirty objects into water source

\footnotetext{
*Water sold at water kiosks costs more than five times what residents in the formal urban areas in Eldoret, who have water meters, pay the municipal council for water.
} 
TABLE 2 Distance between pit latrine and wells for all wells in the study in Langas Slum, Kenya

\begin{tabular}{lcr}
\hline Distance & Number & Percent \\
\hline $1-15 \mathrm{~m}$ & 67 & 38.3 \\
$15-30 \mathrm{~m}$ & 103 & 58.9 \\
$30 \mathrm{~m}$ and above & 5 & 2.9 \\
Total & $175^{*}$ & 100 \\
\hline
\end{tabular}

*This total reflects only wells, and thus excludes taps.

$(34 \%)$ as the main source of contamination, drawing water from the source with dirty containers $(27 \%)$, domestic animals defecating around water sources $(19 \%)$, and people washing clothes $(5 \%)$ at the water source, among others. Interestingly, no one mentioned closeness of the well to the pit latrines as a possible source of contamination.

\section{Water Analysis Results}

Forty water samples were analyzed: 31 from shallow wells, four from deep wells, and five from taps.

\section{Wells}

Shallow Wells All the samples (31) taken from shallow wells were positive for total coliforms. The most probable number of total coliforms for most of the samples $(71 \%)$ was $1,100+$ per $100 \mathrm{ml}$. The minimum number of total coliforms was 63 , whereas the maximum was $1,100+$ coliforms per $100 \mathrm{ml}$ water.

Only one of the samples had no thermotolerant coliforms at all, whereas most had 1,100+ thermotolerant coliforms per $100 \mathrm{ml}$.

Deep (Drilled) Wells Of the four samples taken from the deep wells, three were positive for total coliforms, whereas one was negative. The highest number of total coliforms was 240. For thermotolerant coliforms, two samples were negative. The maximum number of thermotolerant coliforms was 23 .

Taps For the five samples taken from taps (municipal tap water), all of them were negative for total coliforms and consequently thermotolerant coliforms.

TABLE 3 Distance between pit latrine and well for wells whose water was sampled in Langas Slum, Kenya

\begin{tabular}{lcc}
\hline Distance & Number & Percent \\
\hline $1-15 \mathrm{~m}$ & 14 & 40 \\
$15-30 \mathrm{~m}$ & 19 & 54 \\
$30 \mathrm{~m}$ and above & 2 & 6 \\
Total & $35^{*}$ & 100 \\
\hline
\end{tabular}

*This total reflects only wells whose water was sampled, and thus excludes taps. 


\section{DISCUSSION}

This paper provides evidence on the extent of contamination of main domestic water sources in the Langas slum and suggests the most probable sources of this contamination. The evidence reveals that the most probable sources of contamination are hardly mentioned among the many sources perceived to contaminate the water sources by the residents of the slum, which impacts how interventions ought to be developed.

The results indicate that the majority of the community members used pit latrines and at the same time used wells as the major source of domestic water. The conditions found in Langas do not fulfill the recommendations given for coexistence of onsite sanitation and use of ground water for domestic purposes, which indicate that there should be an adequate lateral separation between the pit latrine and the well to reduce chances of fecal contamination of the ground water. ${ }^{16}$ The distance between the wells and the pit latrines was estimated to be generally short with nearly $40 \%$ of the pit latrines estimated to be at a distance of less than $15 \mathrm{~m}$ from the wells. This raises the risk of contamination of the water sources as coliforms migrate from the pit latrines to the wells.

The presence of indicator organisms (Escherichia coli or thermotolerant coliform bacteria) in water indicates recent contamination of the water source with fecal matter and hence possible presence of intestinal pathogens. According to World Health Organization (WHO) guidelines, E. coli or thermotolerant coliform bacteria should not be detectable in any water intended for drinking. ${ }^{18}$ The laboratory analysis results of water samples in this study show that fecal matter heavily contaminated the water sources and especially the shallow wells. None of the shallow wells met the WHO requirements for water intended for drinking. The presence of indicator organisms in the water samples collected from the wells indicates the coliforms migrated from fecal matter in the pit latrines through the soil to the water sources, facilitated by the very short distance between the pit latrines and the wells. Poor sanitary practices are also likely sources of pollution of the water sources. Sanitary practices were found to be generally poor from observation and from responses from the respondents. Thirty percent of children excreted indiscriminately and consequently there were a lot of indiscriminately disposed excreta observed. Rains are likely to wash off indiscriminately disposed excreta into shallow wells particularly if the wells are not protected. Therefore, this may have also contributed to the contamination of the generally open shallow wells with fecal matter. Other studies have also attributed contamination of water sources to wet seasons. ${ }^{19}$ Despite the contamination of water, it was evident that it was not a common practice for the slum dwellers to boil the water, as only $42 \%$ of those who used water from wells said they boiled drinking water.

The illegal status of the slum areas in Kenya has hindered the expansion of municipal services to serve them. This has resulted to the poor being denied access to safer drinking water and proper sanitation. The results of this study suggest that water from the tap (which was from the municipal council) was safe for human consumption according to WHO guidelines. ${ }^{18}$ However, it is important to note that although the presence of thermotolerant coliforms indicates the presence of fecal contamination and potential presence of pathogens, absence of the same does not necessarily mean absence of pathogens, and further investigations would be worthwhile. 
Langas is not the only area with the problem of safe drinking water; other urban centers of the developing world have experienced similar problems. ${ }^{19-22}$ Similar to Langas, in the slums of Nairobi, Kenya, although wells are not a common source of water, slum residents are forced to buy tap water at exorbitant prices from vendors who operate without regulatory mechanisms. ${ }^{23,24}$ If the Millennium Development Goals of reducing by half the proportion of people without sustainable access to safe drinking water by 2015 and achieving a significant improvement in lives of at least 100 million slum dwellers by $2020^{25}$ are to be met, there is a dire need for reconsideration of the slum areas in the developing world as far as water supply is concerned, as these slums are home to about $70 \%$ of all urban residents in sub-Saharan Africa. ${ }^{26}$

However, improving the water quality at source alone may not be the ultimate solution because improving water quality at source may not always ensure a reduction in the transmission of water-related diseases. Studies ${ }^{27-30}$ have shown significant deterioration in water quality between the source and the point of use. Esrey $^{31}$ concluded that improving water had no health impact if the sanitation was not improved and that improving both water and sanitation together were synergistic in producing larger impacts than either alone. Although the results of this study suggest the need for provision of safer water sources, in this community and in many other slum communities with evident poor sanitary practices, intensive behavior change communication on sanitary practices is also paramount as this has been found effective in the reduction of water-borne diseases elsewhere. ${ }^{32-35}$

Whereas the findings from this study are worthwhile and act as an eye opener for the situation of quality of water in the rapidly growing informal settlements in the urban areas in Kenya and in the rest of Africa, more sampling of different water sources is highly recommended.

\section{CONCLUSION}

It is evident that most of the sources of domestic water in Langas slum are contaminated with fecal matter and do not meet the WHO guidelines for drinking water quality. This poses a health hazard to the residents of the slum as they are at risk of water-borne diseases. The results of this study also suggest that tap water may be safer, but additional sampling is needed. The ideal intervention in the longrun may therefore be provision of adequate piped water to all slum dwellers. However, this may take sometime, and simpler interventions could be put in place in the mean time. Basic sanitary improvement may be worthwhile at the moment. Covering the shallow wells and possibly installing hand pumps or mechanical pumps at the wells could improve the situation. Basic treatment of the water at the community or household level by chemical disinfection using chlorine, filtration using simple household filters, and boiling should also be promoted. These interventions may have a great impact on the health of the slum dwellers as access to safe drinking water and basic sanitation services for populations at risk would result in 200 million/year fewer diarrheal episodes and 2.1 million/year fewer deaths caused by diarrhea. ${ }^{35}$

\section{ACKNOWLEDGMENTS}

This study was funded by the African Population \& Health Research Center, the African Medical and Research Foundation (AMREF), and the Moi University, 
Kenya. Data collection was funded by (AMREF) Kenya, Water and Sanitation (WATSAN) project, Eldoret. Analysis of water samples and partial analysis of data was funded by the Moi University. Further data analysis and preparation of this manuscript was funded by the African Population and Health Research Centre (APHRC). We specifically acknowledge Mr. Araka, Mr. Nkonge, and Mr. Obala of Moi University, Dr. Eliya Zulu, Dr. Nyovani Madise, Dr. Fredrick Mugisha, and Dr. Jean Christopher Fotso of APHRC, for technical assistance.

Authors' Contributions EWK-M conceived and designed the study, collected and analyzed the data, developed the manuscript, and gave final approval for publishing.

AN participated in the design of the study, supervised laboratory water analysis and the whole research process, revised the manuscript, and gave final approval for publishing.

\section{REFERENCES}

1. Lamba D. The forgotten half; environmental health in Nairobi's poverty areas. Environ Urban. 1994;6:164-168.

2. Todaro M. Urbanization and rural-urban migration: Theory and policy. In: Todaro M. Economic development in the third world. 4th ed. New York, NY: Longman; 1989:263289.

3. United Nations Center for Human Settlement (UN-HABITAT). An Urbanizing World: Global report on human settlements. Oxford University Press; 1996.

4. African Population and Health Research Center (APHRC). Population and Health Dynamics in Nairobi Informal Settlements. Nairobi: African Population and Health Research Center; 2002.

5. Brockerhoff M, Brennan E. The poverty of cities in developing countries. Popul Dev Rev. 1998;24:75-114.

6. Magadi MA, Zulu EM, Brockerhoff M. The inequality of maternal health care in urban sub-Saharan Africa in the 1990s. Popul Stud. 2003;57:347-366.

7. Taffa N. A comparison of pregnancy and child health outcomes between teenage and adult mothers in the slums of Nairobi, Kenya. Int J Adolesc Med Health. 2003;15:321-329.

8. UNICEF. Poverty and exclusion among urban children. Innocent Digest No. 10, UNICEF Innocent Research Centre. 2002. Available at: http://www.unicef-isdc.org. Accessed October 2006.

9. World Bank. World Development Report 1999/2000. London: Oxford University; 1999.

10. Central Bureau of Statistics (CBS) Kenya. Economic survey 2000. Nairobi: Government Printers; 2000.

11. WHO/UNICEF/WSSCC. Water Supply And Sanitation Sector Monitoring Report 1996 (Sector Status as of 31 December 1994). WHO/EOS/96.15. Geneva: WHO; 1996.

12. United Nations Population Division. World Urbanization Prospects: The 1999 Revision. New York, NY: United Nations; 2000.

13. World Health Organization. Guidelines for Drinking Water Quality, Second edition, Vol. 3. Geneva: WHO; 1997.

14. Murray CJL, Lopez, AD. eds. The Global Burden of Disease, Vol. II. Global Health Statistics: A compendium of incidence, prevalence and mortality estimates for over 200 conditions. Harvard School of Public Health on behalf of the World Health Organization and The World Bank, Cambridge, MA; 1996.

15. WHO/UNICEF. Global Water Supply and Sanitation Assessment. Geneva: World Health Organization; 2000.

16. ARGOSS. Guidelines for Assessing the Risk to Groundwater from On-site Sanitation. Kampala Workshop proceedings, 2001. 
17. Rose Musyoka. Informal Land Delivery Processes in African Cities. Working Paper 4, 2004. Available at: http://www.idd.bham.ac.uk/research/Projects/informal_land/working paper 4.pdf. Accessed March 2007.

18. World Health Organization. Guidelines for Drinking Water Quality, Second edition, Vol. 2. Geneva: WHO; 1996.

19. Hebert JR. On-site water contamination in an urban slum. Water Int. 1983;8:127-132.

20. Joshi SD, Musaddiq M. Studies on distribution of E. coli and Salmonella in drinking water-A six month's survey report. Pollut Res. 2003;22:121-124.

21. Newman RD, Wuhib T, Lima AAM, Guerrant RL, Sears CL. Environmental sources of Cryptosporidium in an urban slum in north-eastern Brazil. Am J Trop Med Hyg. 1993;49:270-275.

22. Molbak K, Hojlyng N, Jepsen S, Gaarslev K. Bacterial contamination of stored water and stored food: A potential source of diarrhoeal disease in West Africa. Epidemiol Infect. 1989;102:309-316.

23. African Population and Health Research Center (APHRC). Health and Livelihood Needs of Residents of Informal Settlements on Nairobi City. Nairobi: African Population and Health Research Center; Occasional Study Report No.1; 2002.

24. Kimani EW, Zulu EM, Undie C. Health and Livelihood Implications of Marginalization of Slum Dwellers in Provision of Water and Sanitation Services in Nairobi City. Poster presentation at the 4th international conference on urban health, 26th to 28th October, 2005 in Toronto, Canada.

25. UN Millenium Development Goals Available at: http://www.un.org/millenniumgoals. Accessed October 2006.

26. UN-Habitat. Slums of the World. The Face of Urban Poverty in the New Millenium? Global Urban Observatory. Nairobi: UN-Habitat; 2003.

27. Genthe B, Strauss N, Seager J, Vundule C, Maforah F, Kfir R. The Effect of type of water supply on water quality in a developing community in South Africa. Wat Sci Tech. 1997;35:35-40.

28. Lindskog P, Lindskog U. Bacterial contamination of water in rural areas. An intervention study from Malawi. J Trop Med. 1988;91:1-7.

29. Mertens TE, Fernando MA, Marshall TF, Kirkwood BR, Cairncross S, Radalowicz A. Determinants of water quality, availability and use in Kurunegala, Sri Lanka. Trop Med Parasitol. 1990;41:89-97.

30. Verweij PE, van Egmond M, Bac DJ, van der Schroeff JG, Mouton RP. Hygiene, skin infections and type of water supply in Venda, South Africa. Trans R Soc Trop Med Hyg. 1991;85:681-684.

31. Esrey SA. Water, waste, and well-being: a multi-country study. Am J Epidemiol. 1996;143:608-623.

32. Ahmed NU, Zeitlin MF, Beiser AS, et al. Community-based trial and ethnographic techniques for the development of hygiene intervention in rural Bangladesh. Int $Q$ Community Health Educ. 1991;12:183-202.

33. Alam N, Wojtyniak B, Henry FJ, Rahaman MM. Mothers' personal and domestic hygiene and diarrhoea incidence in young children in rural Bangladesh. Int J Epidemiol. 1989;18:242-247.

34. Esrey SA, Feachem RG, Hughes JM. Interventions for the control of diarrhoeal diseases among young children: improving water supplies and excreta disposal facilities. Bull World Health Organ Suppl 1985;63:757-772.

35. Esrey SA, Potash JB, Roberts L, Shiff C. Effects of improved water supply and sanitation on ascariasis, diarrhoea, dracunculiasis, hookworm infection, schistosomiasis, and trachoma. Bull World Health Organ. 1991;69:609-621. 